\title{
A Computationally Efficient User Model for Effective Content Adaptation Based on Domain-Wise Learning Style Preferences: A Web-Based Approach
}

\author{
Dong Pan $\left(\mathbb{D},{ }^{1}\right.$ Anwar Hussain $\mathbb{D D}^{2}$ Shah Nazir $\mathbb{D}^{2},{ }^{2}$ and Sulaiman Khan $\mathbb{D}^{2}$ \\ ${ }^{1}$ Southwest Minzu University Information and Educational Technology Center, Chengdu 610041, China \\ ${ }^{2}$ Department of Computer Science, University of Swabi, Swabi, Pakistan \\ Correspondence should be addressed to Dong Pan; pandongdong1126@163.com and Shah Nazir; snshahnzr@gmail.com
}

Received 26 November 2020; Revised 21 December 2020; Accepted 27 February 2021; Published 1 April 2021

Academic Editor: Dr Shahzad Sarfraz

Copyright (c) 2021 Dong Pan et al. This is an open access article distributed under the Creative Commons Attribution License, which permits unrestricted use, distribution, and reproduction in any medium, provided the original work is properly cited.

\begin{abstract}
In the educational hypermedia domain, adaptive systems try to adapt educational materials according to the required properties of a user. The adaptability of these systems becomes more effective once the system has the knowledge about how a student can learn better. Studies suggest that, for effective personalization, one of the important features is to know precisely the learning style of a student. However, learning styles are dynamic and may vary domain-wise. To address such aspects of learning styles, we have proposed a computationally efficient solution that considers the dynamic and nondeterministic nature of learning styles, effect of the subject domain, and nonstationary aspect during the learning process. The proposed model is novel, robust, and flexible to optimize students' domain-wise learning style preferences for better content adaptation. We have developed a web-based experimental prototype for assessment and validation. The proposed model is compared with the existing available learning stylebased model, and the experimental results show that personalization based on incorporating discipline-wise learning style variations becomes more effective.
\end{abstract}

\section{Introduction}

Adaptive systems provide and adapt contents according to the properties of an individual user [1]. In the educational environment, these systems filter and provide educational contents based on the preferences of a student and are known as adaptive educational hypermedia systems $[1,2]$. The user model in these systems is confined and focuses on the features that are associated with the learning aspect of a student $[2,3]$, and learning styles are exploited in the adaptive hypermedia domain as a source of content adaptation [4-6]. By integrating learning styles in the user model, it covers the cognition aspect of human learning, such as how a user learns $[2,3]$. Preferences of learning styles are exploited in a number of ways to solve and address different problems in the domain [7-9]. As a result, learning styles are mainly used in the educational domain where educational contents need to be filtered for the students.
One of the significant features of learning styles is its dynamic and nonstationary aspects that can be changed from domain to domain. Jones in his study [10] investigated and came to the conclusion that learning styles have variations domain-wise. According to his study, significant differences were identified in learning styles for various disciplines, such as Mathematics, Social studies, Science, and English. In order to enhance the adaptation of a learning system, it is important to consider the domain-wise learning style preferences too. Researchers emphasized on incorporating a precise representation of the student needs. As a result, recent models in the literature have the capability to some extent to adjust learning style preferences automatically with the system's usage [11-13]. However, the existing systems still have deficiencies in content adaptation because learning is not an easily quantifiable and continuous process. Due to these properties, most of the approaches are probabilistic for updating learning style preferences instead of deriving the exact measures [14]. 
A number of surveys are conducted in the adaptive educational hypermedia domain that emphasizes on the effectiveness of learning styles for adapting the educational contents $[2,3,15]$. These studies provide useful insights regarding the important variables, models developed, features exploited, and issues faced by these approaches. While studying the recent work, to our knowledge, these approaches mainly work in the content of a single domain $[12,13,15]$. In fact, learning styles are dynamic and can change with the passage of time $[16,17]$. It is not necessary that a student will always have the same learning approach for learning the concept of different academic subjects. For example, it is possible that, for one subject, students prefer examples of the concept, while for the other, theories of concepts are more important. So it is necessary to provide adaptation that also depends upon the need of the subject.

To address a domain-wise aspect of learning styles, we have proposed a domain-wise learning style solution that effectively exploits a student's discipline-specific learning style preferences for content adaptation. The proposed model dynamically and continuously updates student's learning preferences for different academic disciplines accordingly. The proposed solution tries to address student's learning style preferences that are not necessarily the same for multiple disciplines. Furthermore, for assessment and validation of our model, a web-based experimental prototype is developed which adapts contents using the proposed model, and comparison is done with the existing learning stylebased solutions. The experimental results show that the proposed approach exploits student's learning styles in an effective way and enhances the learning process. Following are the main contributions of the study:

(i) To exploit domain-wise learning preferences for effective learning

(ii) To propose a model which has the capability to adjust domain-wise learning style variations for different subject domains

(iii) To provide a computationally efficient solution that can be easily adopted for developing learning systems in the educational hypermedia domain

The rest of the paper is divided into the following sections. Section 2 provides the background and related work to the current research. The proposed models and experimental prototype application are explained in Section 3 and Section 4 , respectively. The research design for the study is given in Section 5. Results are presented in Section 6 while Section 7 is the conclusion of the study.

\section{Background Study}

With the passage of time, applications of computer increases and its scopes span in order to provide more efficient solutions for the problems in different domains. Some of the major applications of computers can be seen in the form of online shopping recommender system, expert system, image processing, artificial intelligence, and so on. In the educational domain, systems try to enhance the user learning process by adapting contents according to the requirements of a user and are called adaptive educational hypermedia systems. Contributions of experts in the field of adaptive educational hypermedia domain have been observed, and their studies mainly focus to make the system capable of understanding the requirements of the user more precisely. The experts believe that, for better adaptation, it is more important for a system to know the user cognitive abilities along with physical capabilities [18]. The cognitive abilities include the learning process of humans and the way people think and process information. As a result, learning style becomes one of the important features to be considered in the user model of these systems. Most of the models of human cognition are exploited to enhance the ability of the system's adaptation. The following sections provide an overview of the most frequent learning style models that are exploited and the approaches used for applying these models in the adaptive educational hypermedia domain.

2.1. Frequently Used Learning Style Models. Experts have used a number of learning style models for content adaptation in the adaptive educational hypermedia domain. Some of them are used more frequently in the literature. The details of these models are given below.

2.1.1. Verbal or Imager Holistic or Analytical. This model categorizes the users into two main categories. These categories include a total of four types of users [19]. The first one is verbal users that understand well from the contents represented in written form. The second is imager users that understand the material which is represented in graphical form. The third is the holistic, who looks at the situation as a whole and uses a top-down approach for concept understanding while the fourth one is analytical which understands the material by individual parts and then combines them.

2.1.2. Kolb's Learning Style. This model [20] is based on experiential learning theory (ELT). It defines that how knowledge is created from experience (Kolb (1984)). According to this model, a learner goes through four modes in a cyclic fashion. These include concrete experience, reflective observation, abstract conceptualization, and active experimentation. According to this model, previous experience has a great contribution in the learning process.

2.1.3. Field Dependent or Independent. This model considers the user's cognitive psychological structure by which a user differentiates contextual information [21]. It mainly divides users into one of the two types such as field dependent and field independent. The field-dependent users are affected by the external environment. Normally, they use nonverbal gestures for conveying their idea and also differentiate things from their context with difficulty. However, the field-independent style users look to the things with their own perspective in mind. They are not affected by others easily, and 
normally, they respond quickly inside a classroom environment.

2.1.4. Felder and Silverman Learning Style. This model is based on four dimensions, and each dimension has two types of users. The first dimension has active and passive learners. Active learners are more experimental, work in groups, and share their ideas while passive learners take more time on thinking before applying experiments. The second dimension has sensing and intuitive learners. The first learner relates knowledge to the world application, more practical, while the former learners are more creative and they like abstract learning content which possesses theories. The third dimension has visual and verbal learners. As their names show, visual learners understand more from the graphical form while verbal learners learn from textual information and verbal explanations. The fourth dimension includes global and sequential learners. Sequential learners tend to develop knowledge step by step from fragments of information and integrate them. On the other hand, global learners see the overall picture first and then go towards the fragments in a top-down manner.

2.2. Modelling Approaches for Adaptive Hypermedia System. Adaptive educational hypermedia systems are the application of adaptive systems in the educational domain [1]. In this case, the domain becomes confined in the context of the user model and contents. The user model includes those features that are associated with the students and hypermedia such as educational contents instead of general information. These systems are categorized into two types based on their adaptation mechanism [22]. One is based on the presentation of contents, called adaptive presentation system, while the other is based on the link level, known as adaptive navigation systems. The adaptive presentation systems adapt contents and present them in different forms. User model in these systems exploits learning styles to associate different forms of contents with the learning type of user. The adaptive navigation systems change the navigation pattern of the content accessibility based on the requirements of the user. These include links disabling, accessing links, and hiding these links. The summary of the number of adaptive presentation and navigation systems is given in Tables 1 and 2. In addition to these two types of systems, there are a number of hybrid approaches that take benefits from the features of both above approaches. Table 3 shows the number of modeling approaches used in the adaptive hypermedia domain.

As shown in Table 3, user models are mainly based on three approaches. These approaches are overlay, stereotype, and combination of the former two models [36]. According to the survey $[2,3]$, user knowledge is one of the most important features that are being considered for adaptation. Systems that are based on overlay model are HYPERFLEX [37, 38], Adaptive Hypermedia Architecture System (AHA)! [26], and ISIS-Tutor [33]. HyperTutor [39] is based on the stereotype user model. In the stereotype user model-based system, the user is assigned to a category or type as we have seen in different learning style models. Some of the systems use diverse approaches that benefit from more than one modeling approach. These systems include ANATOM-TUTOR [24], ELM-ART [22], Interbook I, and Avanti.

Furthermore, Abyaa et al. [15] have done a detailed survey on the modeling approaches, variables exploited, and learning factors that are used in the learner model. Survey analysed and categorized the characteristic of the modeling approaches. Their analysis shows that, among different characteristics, some of the most important characteristics are exploited more frequently in the past. These include learner's knowledge and their cognitive abilities that are reflected in the system by incorporating learning style preferences in the user model.

In short, incorporating learning styles for content adaptation in the adaptive system is an important and focused area for experts $[14,15,40]$. Studies try to enhance students learning outcomes such as open learning model (OLM) [41]. Furthermore, current studies mainly focus on how to minimize the gap between user learning behavior and system adaptation level [42-44]. In order to minimize this gap, the learning styles of the user are required to be modelled in a way that should reflect the true needs of the user. One of the main properties is the domain-wise learning style variations, which has not been taken into account, and the previous system is used to update these learning styles in the context of a single domain. However, our work considers this important dimension in the adaptation process, such as domain-wise learning style variations.

\section{Proposed Model}

The domain-wise adaptive (DWA) model is inspired from $[45,46]$, where the proposed research has made it capable of handling discipline-specific variations in learning style. Learning style preferences are represented by real values so that they can be exploited in an environment where moderate preferences are necessary to be considered. Preferences of users are identified via a learning style questionnaire. Furthermore, these preferences are updated according to the requirements of the subject's domain. The problem definition along with the contribution of the proposed study is shown in Figure 1. The following sections show the main contribution of the proposed study.

3.1. Learning Styles of the User. Learning style model assigns users to one of the 16 learning style preferences. Preferences are mainly the combination of four dimensions of ILS. Every dimension categorizes users into two types (preferences). Detail of the dimensions, their purpose, and their associated preferences are shown in Table 4. Learning style is a collective measure that combines all of the four dimensions for a user and is represented by the following equation:

$$
\mathrm{LSC}=\left\{a \in\left(\frac{\mathrm{Act}}{\mathrm{Ref}}\right), b \in\left(\frac{\mathrm{Vis}}{\mathrm{Ver}}\right), c \in\left(\frac{\mathrm{Se}}{\mathrm{In}}\right), d \in\left(\frac{\mathrm{Glo}}{\mathrm{Seq}}\right)\right\} .
$$


TABLE 1: Several adaptive presentation systems in the adaptive hypermedia domain.

\begin{tabular}{|c|c|c|c|c|c|c|c|}
\hline System type & Technique used & Proposed system & Background & Goals & Preferences & Knowledge & $\begin{array}{l}\text { Hyperspace } \\
\text { experience }\end{array}$ \\
\hline \multirow{7}{*}{ Presentation } & $\begin{array}{l}\text { Adaptive link annotation/ } \\
\text { sorting }\end{array}$ & ELM-ART [22] & No & No & No & Yes & No \\
\hline & Fragments are altered & \multirow{2}{*}{$\begin{array}{c}\text { TANGOW [23] } \\
\text { ANATOM-TUTOR } \\
{[24]}\end{array}$} & No & Yes & Yes & No & No \\
\hline & Fragments are altered & & Yes & No & No & Yes & Yes \\
\hline & $\begin{array}{l}\text { Fragments are inserted or } \\
\text { removed or altered }\end{array}$ & WHULEHM [25] & No & No & No & Yes & No \\
\hline & $\begin{array}{l}\text { Fragments are inserted or } \\
\text { removed or altered }\end{array}$ & AHA! [26] & Yes & No & No & No & No \\
\hline & $\begin{array}{l}\text { Fragments are inserted or } \\
\text { removed or altered }\end{array}$ & C-book [27] & Yes & No & No & No & No \\
\hline & Fragments are stored & Hypadapter [28] & No & No & Yes & Yes & No \\
\hline
\end{tabular}

TABLE 2: Several adaptive navigation systems in the adaptive hypermedia domain.

\begin{tabular}{|c|c|c|c|c|c|c|c|}
\hline System type & Technique used & $\begin{array}{c}\text { Proposed } \\
\text { system }\end{array}$ & Background & Goals & Preferences & Knowledge & $\begin{array}{l}\text { Hyperspace } \\
\text { experience }\end{array}$ \\
\hline \multirow{12}{*}{ Navigation } & Stretchtext & Metadoc [29] & Yes & No & No & Yes & No \\
\hline & Adaptive link annotation/hiding & AHA! [26] & No & No & No & Yes & No \\
\hline & Direct guidance & SHIVA [30] & No & No & No & Yes & No \\
\hline & Direct guidance, hiding links & HyperTutor & No & No & No & Yes & Yes \\
\hline & Direct guidance, hiding links & Netcoach [31] & No & Yes & Yes & Yes & No \\
\hline & Direct guidance, hiding links & Interbook [32] & No & No & No & Yes & No \\
\hline & $\begin{array}{c}\text { Direct guidance, link annotation, } \\
\text { hiding links }\end{array}$ & ISIS-Tutor [33] & No & No & No & Yes & No \\
\hline & Disable links, link sorting & TANGOW [23] & Yes & Yes & Yes & No & No \\
\hline & Disable links, link sorting & TANGOW [23] & Yes & Yes & Yes & No & No \\
\hline & Link annotation & ITEM/PG [34] & No & No & No & Yes & No \\
\hline & Link hiding & $\begin{array}{c}\text { Hypadapter } \\
{[28]}\end{array}$ & No & No & Yes & Yes & No \\
\hline & Removal of links & CHEOPS [35] & No & No & No & Yes & No \\
\hline
\end{tabular}

TABLE 3: Adaptive hypermedia system modeling approaches.

\begin{tabular}{lcccc}
\hline S. no & System proposed & Overlay-based models & Stereotype-based models & Hybrid approach \\
\hline 1 & AHA & Yes & No & No \\
2 & INTERBOOK & No & No & Yes \\
3 & Avanti & No & No & Yes \\
4 & HYPERFLEX & Yes & Yes & No \\
5 & HyperTutor & No & No & Yes \\
6 & ANATOM-TUTOR & No & No & No \\
7 & AHM AND XAHM & Yes & No & No \\
8 & ISIS-Tutor & Yes & No & Yes \\
9 & ELM-ART & No & & \\
\hline
\end{tabular}

Based on equation (1), the following 16 learning style preferences are obtained: LSCs $=\{($ Ref, Se, Vis, Seq $),($ Ref, Se, Vis, Glo), (Act, Se, Vis, Seq), (Act, Se, Vis, Glo), (Act, Se, Ver, Seq), (Act, Se, Ver, Glo), (Ref, Se, Ver, Seq), (Ref, Se, Ver, Glo), (Act, In, Vis, Seq), (Act, In, Vis, Glo), (Act, In, Ver, Seq), (Act, In, Ver, Glo), (Ref, In, Vis, Seq), (Ref, In, Vis, Glo), (Ref, In, Ver, Seq), and (Ref, In, Ver, Glo)\}

3.2. Identification of Learning Styles. As we know, learning is not easily quantifiable to be measured; therefore, each learning style preference is shown by its probability. The total probability of each dimension is 1 , while the preference inside shares part of it. For example, if the probability of visual preference is $x$, then the probability of verbal preference will be $(1-x)$. The total probability becomes 1 , such that $x+(1-x)$. Detail of probabilities and their relationship are given in Table 5.

Preferences' probability is calculated from the questions associated with each dimension. The ILS consists of 11 questions for each dimension, having a total of 44 questions for 4 dimensions. The students answer these questions, and if the number of answers associated with preference $A$ is more than that associated with preference $B$, then the user gets learning style having preference $A$. The general formula for learning style preference calculation is given by 


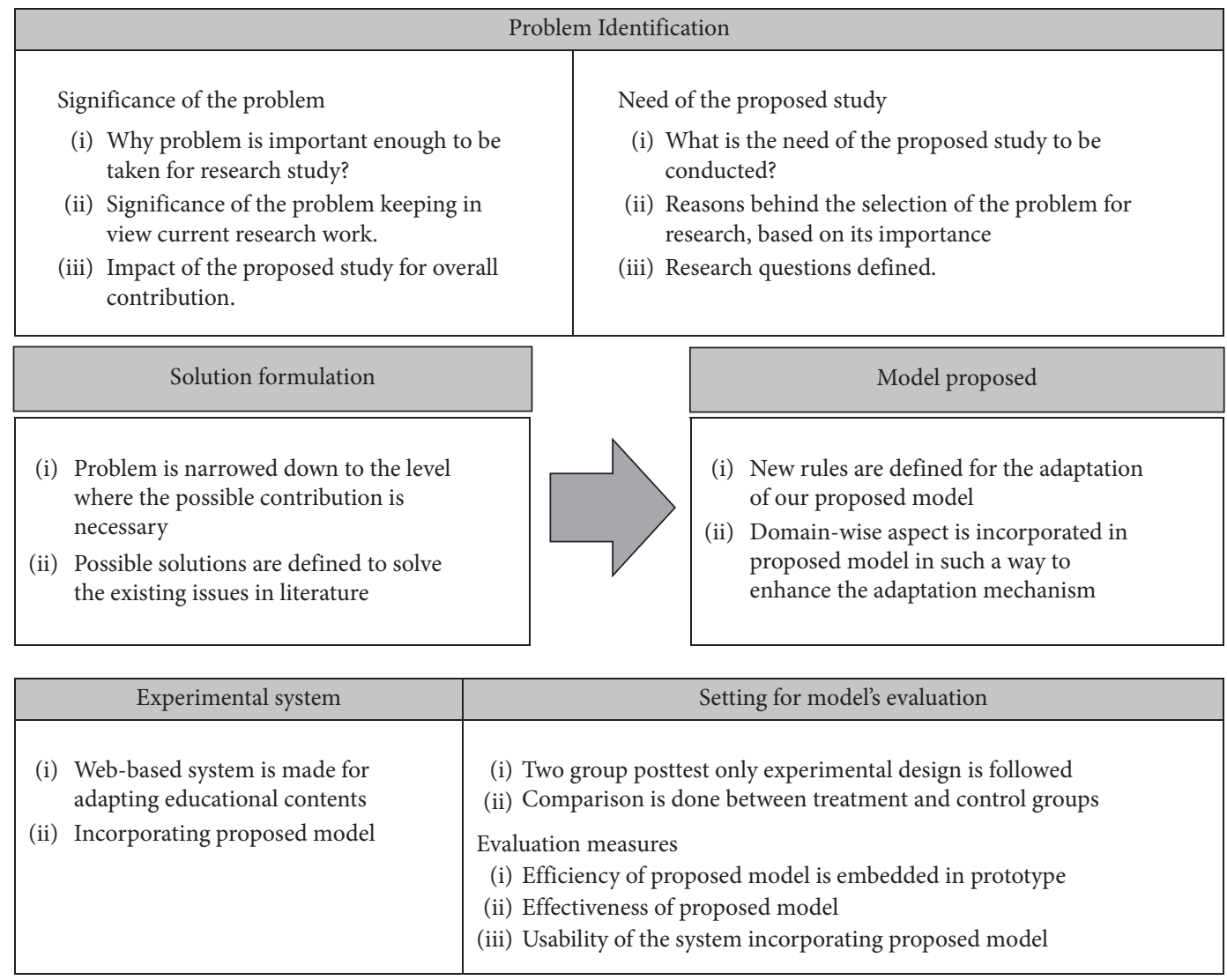

\begin{tabular}{|l|l|}
\hline \multicolumn{2}{|c|}{ Evaluation of the propose study } \\
\hline $\begin{array}{l}\text { Control group } \\
\begin{array}{l}\text { (i) Includes those participants that used } \\
\text { existing models adaptation }\end{array}\end{array}$ & $\begin{array}{l}\text { Experimental group } \\
\text { (ii) } \begin{array}{l}\text { Includes those participants that used proposed } \\
\text { models adaptation } \\
\text { assessment of existing models using } \\
\text { evaluation measures }\end{array}\end{array}$ \\
\hline (ii) Posttest questionnaire is asked for assessment of \\
models evaluation measures
\end{tabular}

FIgURE 1: Overall approach for research.

TABLE 4: Learning style categories.

\begin{tabular}{|c|c|c|c|}
\hline $\begin{array}{l}\text { S } \\
\text { no }\end{array}$ & Learning style dimension & User type A & User type B \\
\hline A & $\begin{array}{c}\text { The way information is } \\
\text { processed }\end{array}$ & Active & Reflective \\
\hline B & How contents are represented & Visual & Verbal \\
\hline $\mathrm{C}$ & $\begin{array}{c}\text { The way user perceives } \\
\text { information }\end{array}$ & Sensing & Intuitive \\
\hline $\mathrm{D}$ & $\begin{array}{l}\text { Learner's perspective on } \\
\text { information }\end{array}$ & Sequential & Global \\
\hline
\end{tabular}

$$
\operatorname{Pr}_{i}=\frac{A_{i}}{11}
$$

where $P r_{i}$ represents the probability for dimension $i, A_{i}$ represents the number of answers that favour learning preference $A$ in dimension $i$, and 11 in the equation is constant because the ILS questionnaire assesses each dimension with the help of 11 questions. This procedure is repeated for all the remaining 3 dimensions.

After calculating the preference for all the four dimensions, preferences are initially stored the same for all the subjects as shown in Table 6. When a student uses the system, then the user model updates these preferences based on the difficulty a student faces in the subject. As learning style variations exist for different subjects, therefore, a student may face more difficulty in a subject as compared to the other. In such a case, the proposed model will update these preferences for each subject accordingly. 
TABLE 5: Representation of preferences' probabilities.

\begin{tabular}{lccc}
\hline Dimension & 1st preference & 2nd preference & Dimension total probability $=1$ \\
\hline $\mathrm{a}$ & $\operatorname{Prob}_{(\mathrm{Act})}=w$ & $\operatorname{Prob}_{(\mathrm{Ref})}=1-w$ & Prob $_{(\mathrm{Act})}+$ Prob $_{(\mathrm{Ref})}=1$ \\
$\mathrm{~b}$ & $\operatorname{Prob}_{(\mathrm{Se})}=x$ & $\operatorname{Prob}_{(\mathrm{In})}=1-x$ & Prob $_{(\mathrm{Se})}+$ Prob $_{(\mathrm{In})}=1$ \\
$\mathrm{c}$ & $\operatorname{Prob}_{\mathrm{Vis}}=y$ & $\operatorname{Prob}_{(\mathrm{Ver})}=1-y$ & Prob $_{(\mathrm{Vis})}+$ Prob $_{(\mathrm{Ver})}=1$ \\
$\mathrm{D}$ & $\operatorname{Prob}_{(\mathrm{Seq})}=z$ & $\operatorname{Prob}_{(\mathrm{Glo})}=1-z$ & Prob $_{(\mathrm{Seq} 0}+$ Prob $_{(\mathrm{Glo})}=1$ \\
\hline
\end{tabular}

Table 6: Preference values before.

\begin{tabular}{lccccccccc}
\hline S. no & Subject & Prob (Act) & Prob (Ref) & Prob (Se) & Prob (In) & Prob (Vis) & Prob (Ver) & Prob (Glo) & Prob (Seq) \\
\hline 1 & Subject 1 & 0.4 & 0.6 & 0.30 & 0.70 & 0.20 & 0.80 & 0.35 \\
2 & Subject 2 & 0.4 & 0.6 & 0.30 & 0.70 & 0.20 & 0.80 & 0.35 & 0.65 \\
\hline
\end{tabular}

For the same user, learning style preferences are adjusted according to the requirement of the subject domain. Table 7 shows the learning style preferences for subject 1 and subject 2 for the same user. In order to identify that how much a student faces difficulty in a particular subject, this decision depends upon the performance of the student in the tests just like taking quizzes or exams [13, 14, 40,47]. In the literature, the main criteria for updating the learning style preferences are based on the assessment of student's performance.

In the proposed model, the assessment criteria for updating learning preferences are based on the student's performance. User preferences are updated when a learning difficulty arises. For example, if a user has good performance in a subject and passes the test, then learning style preferences will not be updated. It will be assumed that the current learning style is suitable and the student is performing well. On the other hand, if the performance is not satisfactory, then the model will be updated. Our model will update learning style preferences only for that particular subject. For achieving this phenomenon, we have proposed some adaptation rules to be incorporated in the user model.

3.3. Proposed Rules for Adaptation. For the system's adaptation and updating learning style preferences, we have proposed some rules, which are mathematically represented and shown in Algorithm 1. The key element for decisionmaking in our approach is the performance of the student. Measuring the performance of the student is represented by " $\mathrm{m}$ " which is the desired performance. The brief description is as follows: if a student performance Perf [ $\operatorname{sub}_{j}$ ] is less than the desired performance $P_{\text {measure }}$ in a subject $j$, then the model has to be updated subtracting the current learning style preferences by some factor $R\left[\mathrm{sub}_{j}\right]$ and add this $R\left[\mathrm{sub}_{j}\right]$ to the learning style preference which is missing. $R\left[\mathrm{sub}_{j}\right]$ is called the reinforcement value.

In Algorithm 1, the description of each element is as follows:

$P_{\text {measure }}$ : performance measure, i.e., $P_{\text {measure }}=60$

$i$ : learning style categories or dimension, which varies in range $i=1 \ldots 4$

$j$ : numbers given to the subject; if we have $n$ number of subjects, then $j$ ranges from $[1-n]$
Perf $\left[\right.$ sub $\left._{j}\right]$ : performance of the student in $j_{\text {th }}$ subject; $\operatorname{Perf}\left[\mathrm{sub}_{j}\right]$ values vary in the range $[0-100]$

LSC $\left[\operatorname{dim}_{i}\right]\left[\operatorname{sub}_{j}\right]$ : learning style currently used for $i_{\text {th }}$ dimension and $j_{\text {th }}$ subject

$\mathrm{SM}\left[\operatorname{dim}_{i}\right]\left[\operatorname{sub}_{j}\right]_{A}$ : learning style for preference $A$ for $i_{\text {th }}$ dimension and $j_{\text {th }}$ subject

$R\left[\operatorname{sub}_{j}\right]$ : the reinforcement to be made for eliminating difficulty for $j_{\text {th }}$ subject; $R\left[\mathrm{sub}_{j}\right]$ varies in the range [0-1] and may not be the same as $R\left[\operatorname{sub}_{j+1}\right]$ or $R\left[\operatorname{sub}_{j-1}\right]$

It is essential to note that the user model will be updated whenever a student does not perform well. Reinforcement $R\left[s_{j}\right]$, as we can see in equation (3), has an inverse relationship with student performance as well as the distance between learning style preferences DLS $\left[s_{j}\right]$. Inverse relation is due to the fact that if student performance is too low, then it means that current learning style preference is not a true representation of the user learning style and needs to be changed by a higher factor. In the case of the distance between learning style preferences, inverse relationship makes sense because when this difference is little then learning style preferences are not considered on either side significant.

$$
R\left[\mathrm{sub}_{j}\right]=\frac{1}{\operatorname{Perf}\left[\mathrm{sub}_{j}\right] * \operatorname{DLS}\left[\mathrm{sub}_{j}\right]} .
$$

DLS can be calculated from equation (4). The value of $R\left[\mathrm{sub}_{j}\right]$ is restricted not to be too high or too low. In the case of high value, the change in learning style preference will not be gradual. On other hand, in the case of low value, the system will take long time to update the learning style preferences to meet the desire learning style of the user. Based on the experimentation in $[45,46]$, the maximum value for $R\left[\mathrm{sub}_{j}\right]$ is suggested to be 0.05 and the minimum value for $R\left[\mathrm{sub}_{j}\right]$ is 0.02 . The proposed model has restricted the higher and lower values for $R\left[\mathrm{sub}_{j}\right]_{\mathrm{Max}}$ and $R\left[\mathrm{sub}_{j}\right]_{\mathrm{Min}}$ to 0.05 and 0.02 , respectively.

$$
\operatorname{DLS}\left[\operatorname{sub}_{j}\right]=\left|\operatorname{SM}\left[\operatorname{dim}_{i}\right]\left[\operatorname{sub}_{j}\right]_{A}-\operatorname{SM}\left[\operatorname{dim}_{i}\right]\left[\operatorname{sub}_{j}\right]_{B}\right| \cdot
$$


TABle 7: Preference values after.

\begin{tabular}{|c|c|c|c|c|c|c|c|c|c|}
\hline S. no & Subject & Prob (Act) & Prob (Ref) & Prob (Se) & Prob (In) & Prob (Vis) & Prob (Ver) & Prob (Glo) & Prob (Seq) \\
\hline 1 & Sub & 0.35 & 0.65 & 0.10 & 0.90 & 0.60 & 0.40 & 0.45 & 0.55 \\
\hline 2 & Subject 2 & 0.70 & 0.30 & 0.35 & 0.65 & 0.33 & 0.67 & 0.25 & 0.75 \\
\hline
\end{tabular}

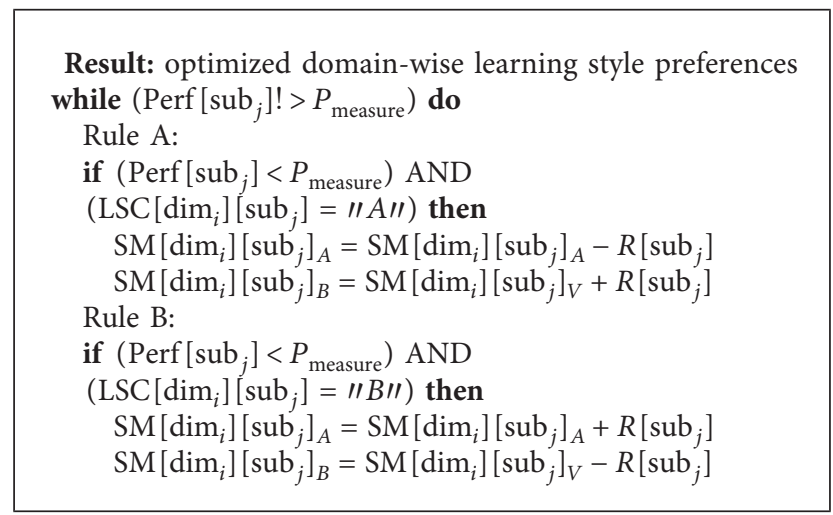

Algorithm 1: Algorithm for updating domain-wise learning style preferences.

\section{Development of Experimental Prototype Application}

An experimental prototype is developed to assess the effectiveness of the proposed model. The prototype is developed by using web programming constructs such as PHP, MySQL, JavaScript, and CSS. Details of the prototype are given in the following sections.

4.1. Selection of Learning Style Model. For capturing students' learning preferences and profile generation, the ILS questionnaire (proposed by Felder and Silverman) is used. The reason behind its selection is that learning style categories and types of users are more suitable for the coursework hypermedia $[11,13,48,49]$. ILS model has also the suitability to the user's categories as well as the nature of educational contents. Detail of its categories and users' preferences is given in Table 4. Identification of user preferences, content adaptation, and updating preferences has been done using the procedures and rules discussed in Section 3.

4.2. Dataset. For the developed system, the dataset is developed from the educational contents of the Virtual University of Pakistan. The dataset includes text documents, PowerPoint slides, and videos. Educational contents from the selected source are more reliable as compared to the other Internet sources because these are prepared by subject experts, specialists, and professors. For the assessment of our proposed model, videos and textual document are used for subjects' lectures. PowerPoint presentations are not used as a learning material because they did not have much explanation regarding the concept. In addition, for the inclusion/ exclusion of the educational contents in our prototype, suggestions from the experts were also taken into account. The experimental prototype setup is made only for two subjects, that is, database and programming. Furthermore, the prototype is capable of any extension to include more subjects. Videos and lectures are further refined to the topic level, and each topic has two forms of representation because topics can provide the basis for successful personalization [50]. The hierarchical structure of these contents is shown in Figure 2.

4.3. Prototype Architecture. The main architecture of the prototype consists of the main four components as shown in Figure 3. A brief description of each of the components is given as follows.

4.3.1. User Model. It is the most significant module of the experimental prototype. The user model is responsible for capturing learning style preferences of the user. The adaptation module uses these learning style preferences to select educational contents. These preferences are updated time to time.

4.3.2. Database of Contents. This component acts as a repository for the system. Different forms of educational content are kept in this module. After identifying learning style preferences from the user model, the adaptation module then filters contents from the database to provide educational material according to the user's preferences.

4.3.3. Interface Module. It provides an interface for students to interact with the system. It is responsible to capture information through the ISL questionnaire. The captured information is then transformed into the user model. Contents filtered by the adaptation model are represented by interface module. The responsibility of the interface module is to present the adapted contents to the user, to capture user 


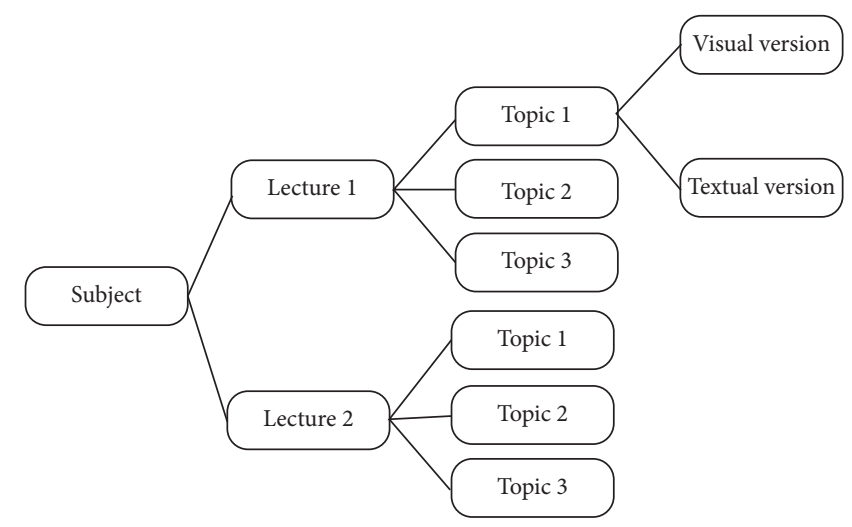

Figure 2: Hierarchical representation of course contents.

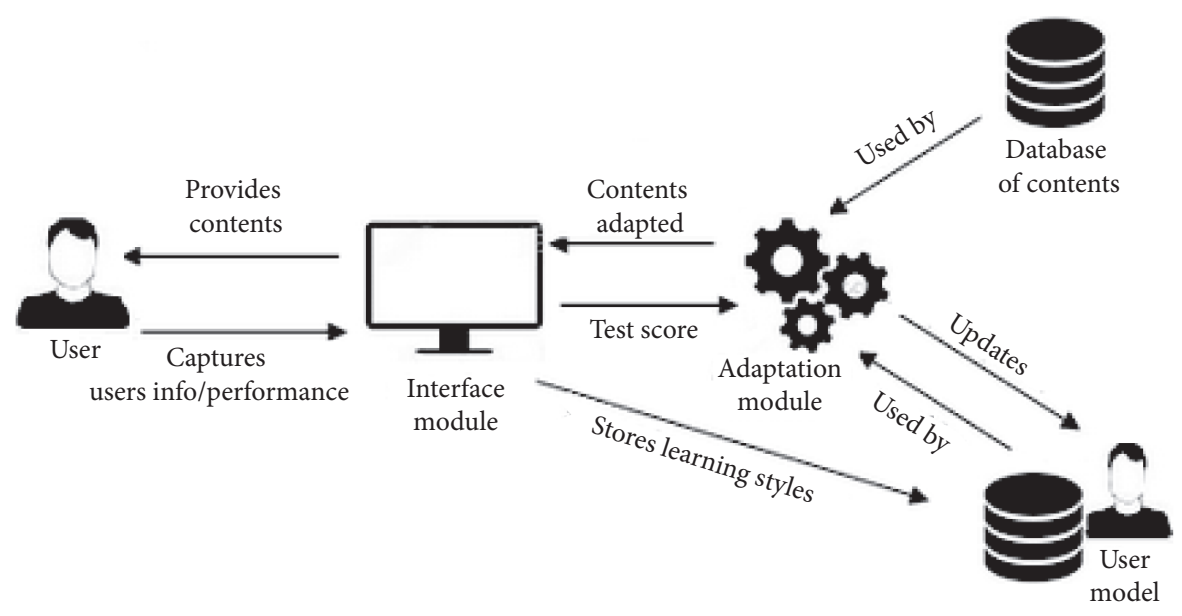

Figure 3: Architecture of prototype.

learning style preferences, and to provide test sessions to the user. The interface layout of our application is shown in Figure 4.

4.3.4. Adaptation Module. The adaptation module consists of rules which filter and select contents from the database. It is the decision-making component of the system. It exploits information of the user model, database of contents, and information coming from the interface model. Using the information of different components, it decides the suitability of contents and updates learning style preferences in order to provide more accurate system adaptation.

4.4. Adaptation Mechanism. The prototype has main four components which are discussed above, and these components are working together around the following four steps.

4.4.1. User Profile Generation. In the first step, a new user is asked to register himself and create his profile, a questionnaire is provided by the interface module, and the user provides information about learning style preferences. Based on the user information, a category is assigned which is then used by the adaptation module.
4.4.2. Providing Adaptive Contents. After capturing user preferences, an initial model for the user is generated. Contents are selected/filtered and provided to the user. Our model is capable of handling subject-wise learning style preferences, so different contents can be selected for different subjects based on the stored learning style preferences.

4.4.3. Assessment of User Learning. One of the most significant tasks is to know the effectiveness of the system. For this purpose, at the end of each session, the user is asked to perform a test. If user performance is satisfactory, then the next lecture is unlocked and learning styles are not updated. It is assumed that current system adaptation is effective for his learning as his performance is satisfactory. In contrast, if the student failed the test, then its learning style preferences are updated in order to optimize the suitability of system adaptation with user learning style. After updating learning styles, the same lecture is provided with more filtered parameters. The user is asked to study the lecture again.

4.4.4. Updating User Preferences Domain-Wise. The proposed model updates user preferences according to the requirement of the subject domain. In our case, when a 


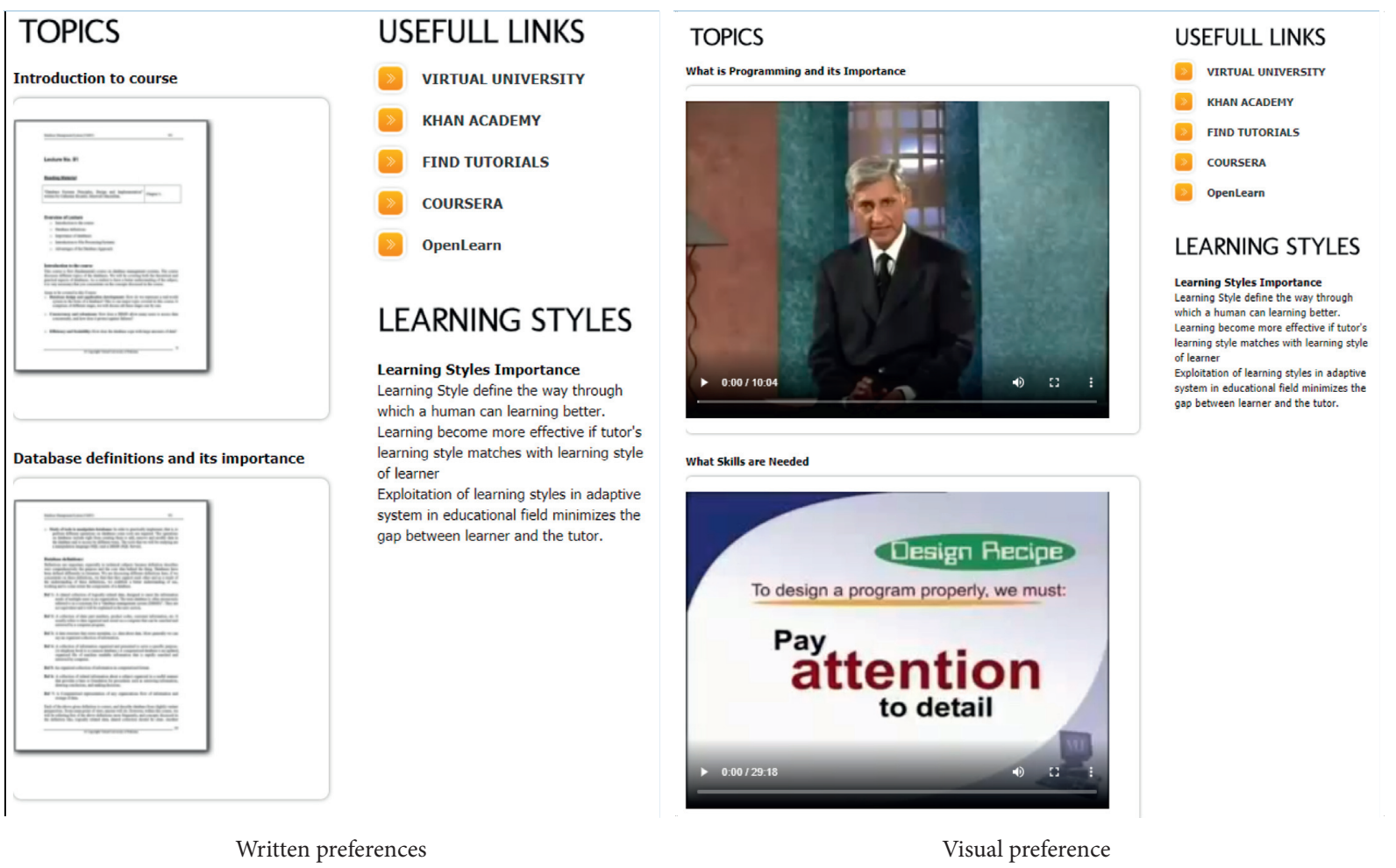

FIGURE 4: Interface for visual and written preferences.

student does not perform well in a subject, then preferences are updated only for that subject. This approach updates preferences in a more optimized way and reflects the true needs of learners.

\section{Research Design}

The proposed model is evaluated by comparing with the exiting learning style model using two-group posttest only randomized experimental design. Among 43 students, finally, 30 participants were chosen randomly for the study. These participants are undergraduate students from the computer discipline. Questionnaire (ILS) is used for the identification of participants' learning style preferences. For identifying 30 students for the control and experimental groups with unbiased learning style preferences, a pretest is taken from 43 students. After achieving the required number of 15 visual and 15 verbal learning preferences for students, these participants are randomly assigned to the control and experimental groups. At the end, each group has half participants of each learning preference in order to avoid group difference formation. To see the distribution of the control and experimental groups, independent-samples $T$-test is applied. For $95 \%$ confidence interval and 0.05 value of alpha, the $p$ value is obtained 0.860 which shows that the difference among groups is not significant. This shows that the group's formation is unbiased which ensures the validity of the evaluation process. Figure 5 shows the overview of the research design followed for the evaluation of the proposed model.
5.1. Overview of Research Design. Participants of the control group have used application based on the existing models, for one week. On the other hand, the experimental group used our proposed experimental prototype application for the lectures. After a week, postsurvey was done from both groups' participants to assess that whether the proposed system is effective in enhancing the learning of the students. Postsurvey includes qualitative as well as quantitative measure for the assessment of the proposed model. In addition, the performance history is also kept into account to know the level of difficulty the users face in these subjects.

5.1.1. Evaluation Criteria for the Proposed Model. The usefulness of the proposed model is measured by using three aspects. These aspects are efficiency, effectiveness, and user satisfaction $[2,3]$. A total of 13 questions were used for these aspects. Efficiency is measured using task-based measures, six questions were aimed to address the effectiveness, and the remaining four questions were for the assessment of user satisfaction. The detail of the evaluation measures is shown in Table 8

\section{Results and Discussions}

The proposed model is compared with the existing models in the literature. For this purpose, students were divided into two groups. One group is the control group and the other is the experimental group. The control group was assigned the task to learn in one-week duration using exiting adaptation, while our developed experimental prototype is given to the 


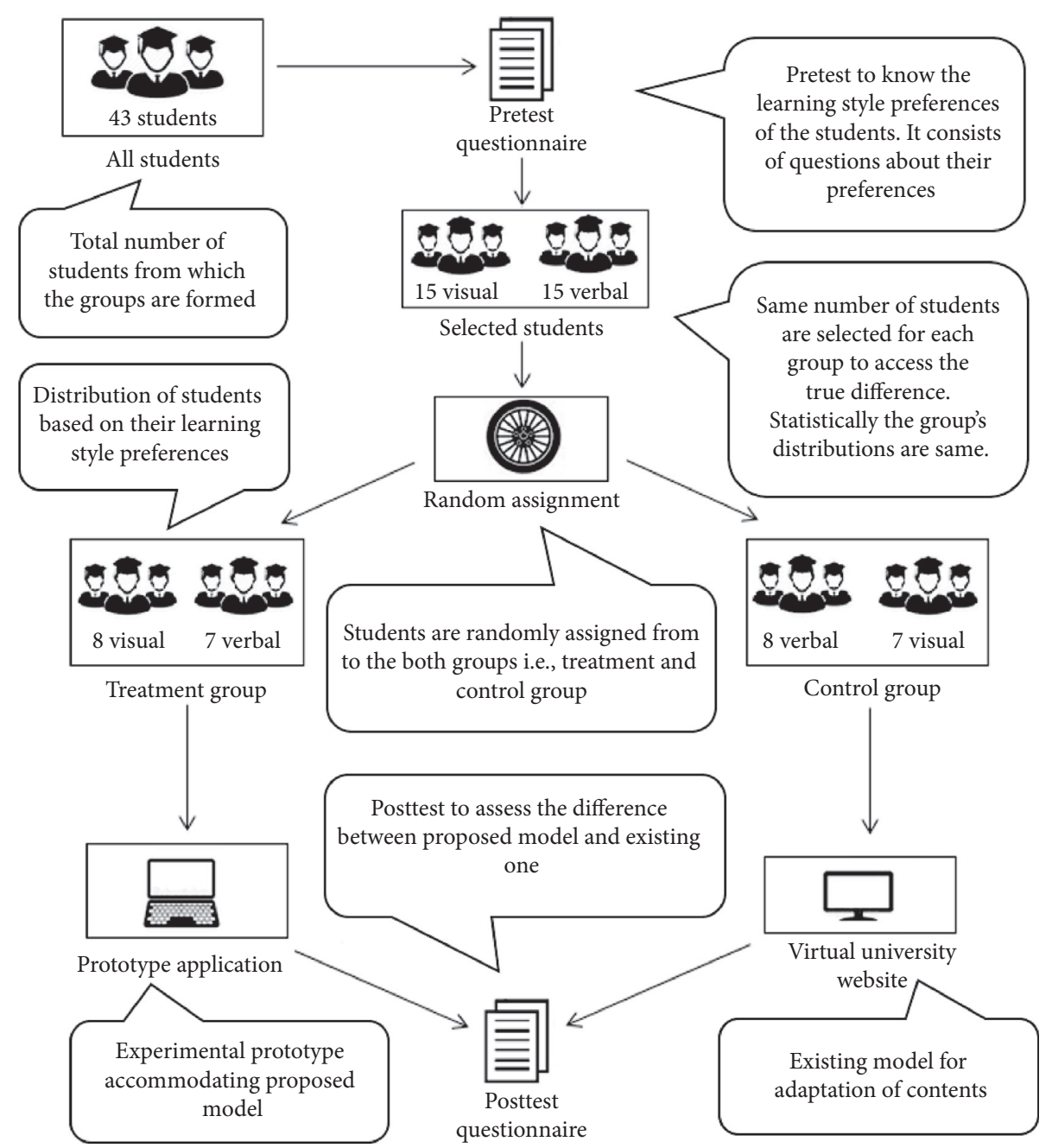

FIGURE 5: Overview of research design.

TABLE 8: Evaluation measures.

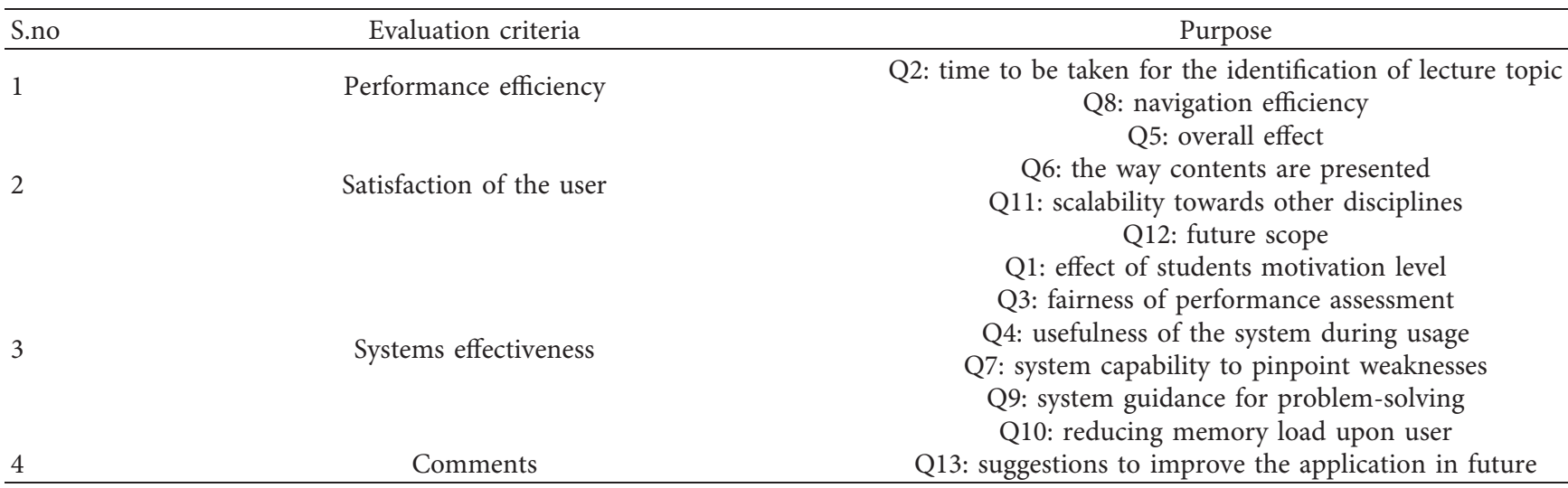

experimental group to do the same task. At the end of one week, the performance of both groups along with postsurvey was evaluated to assess the effectiveness of the proposed model for enhancing learning. The model is evaluated based on the aspects as given in Table 8 .

For the assessment of each evaluation measure, we have performed statistical tests to know its effectiveness. To achieve that, we have used the IBM SPSS tool for performing these tests. Based on the nature of data and scale of measurement taken, independent-samples Mann-Whitney U test is applied in our study's setting. Null hypothesis is considered for each variable. In the case of significant effect size, the test rejects the null hypothesis for the observed variable. Detail of these tests is discussed in subsequent sections. 

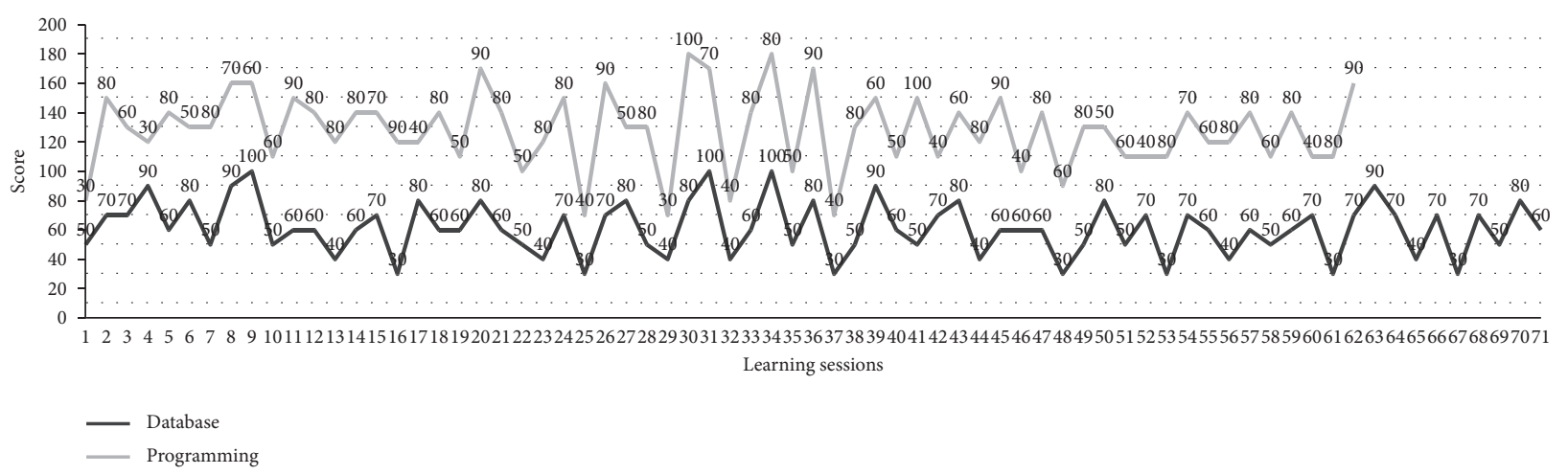

FiguRE 6: Domain-wise performance.

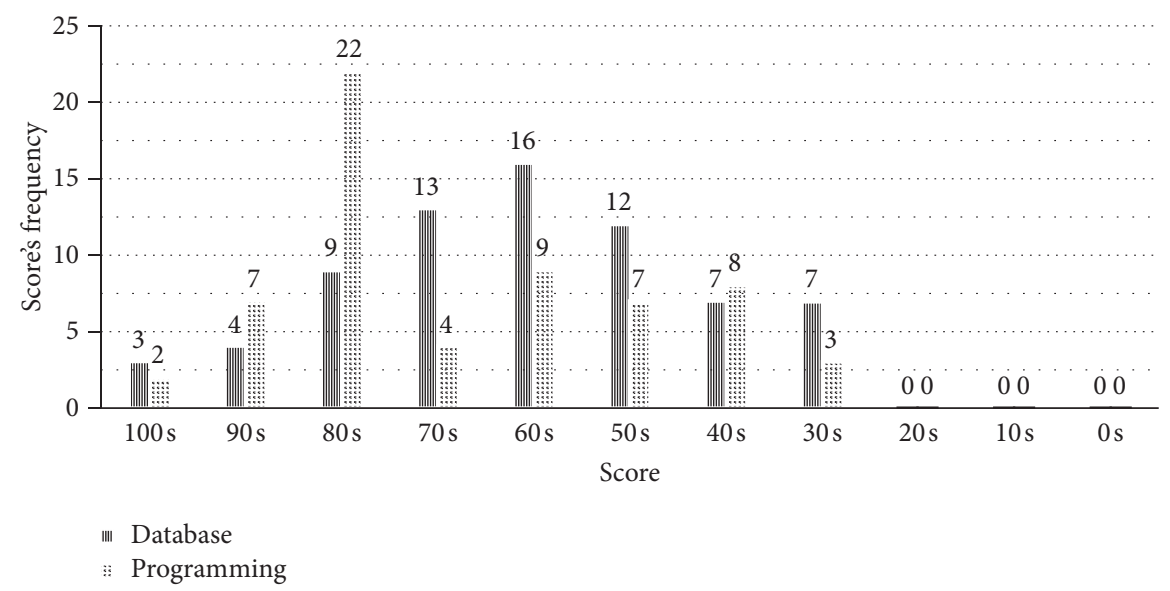

FiguRE 7: Student performance score.

6.1. Domain-Wise Student Performance. As we have discussed that learning styles vary domain-wise. For this purpose, the history of the student learning session and its performance were recorded for each learning session. After each learning session, student performance was assessed through the test. If a student did not score (passing criteria), then the next lecture is not available for the user and was instructed to learn the same lecture again and pass the test. In case of success, the next lecture is provided. Using these criteria, students were instructed to complete the lessons as shown in Figure 6. Furthermore, detail of students' performance is shown in Figure 7.

At the end, we have compared the performances and learning sessions required for both subjects to know whether our claim for domain-wise learning style variation is true or not. From the analysis, it has been identified that there are significant performance differences in these subjects for students as shown in Figure 6. We can see that, in Database subject, student faces more difficulty and learning styles have been changed time to time while on other hand, the students face less difficulty and complete the lectures in a less number of sessions.

The difference is assessed via a statistical test for the confidence interval of $95 \%$. Table 9 shows the detail of the test, the null hypothesis for each variable, and the results of the test. From Table 9, we can see that the null hypothesis is rejected for students' performance score which shows that difference is significant and students do face different levels of difficulty for the subject domain. It proves that learning styles need to be adjusted for each subject domain accordingly to enhance system effectiveness.

6.2. Performance Efficiency. Performance efficiency includes those aspects that define how much the proposed model enhances the efficiency of the system. These aspects include navigation efficiency, which is assessed that how much time a user takes to identify all individual topics of a lecture. Another measure for navigation efficiency is that how quickly a user navigates among different topics for understanding a lesson. These assessments were task-based, and time has been recorded for each user activity for both groups. Based on the evaluation, the proposed model significantly enhances the navigation efficiency of the system as shown in Figure 8.

Details of the test for efficiency are given in Table 10. We have performed independent-samples Mann-Whitney U test on the SPSS software for confidence interval with $95 \%$. The test rejects the null hypothesis for $p$ value less than 0.05 for both factors as shown in Table 10 which means that the difference is statistically significant and our models enhance the navigation efficiency of the system. 
TABLE 9: Students' performance analysis.

\begin{tabular}{lcccc}
\hline S. no & Null hypothesis for the measure & Test conducted & Sig. & Result \\
\hline 1 & User performance is the same for both groups & Independent-samples Mann-Whitney $U$ test & .043 & Null hypothesis is rejected \\
Level of significance is 0.05 & &
\end{tabular}

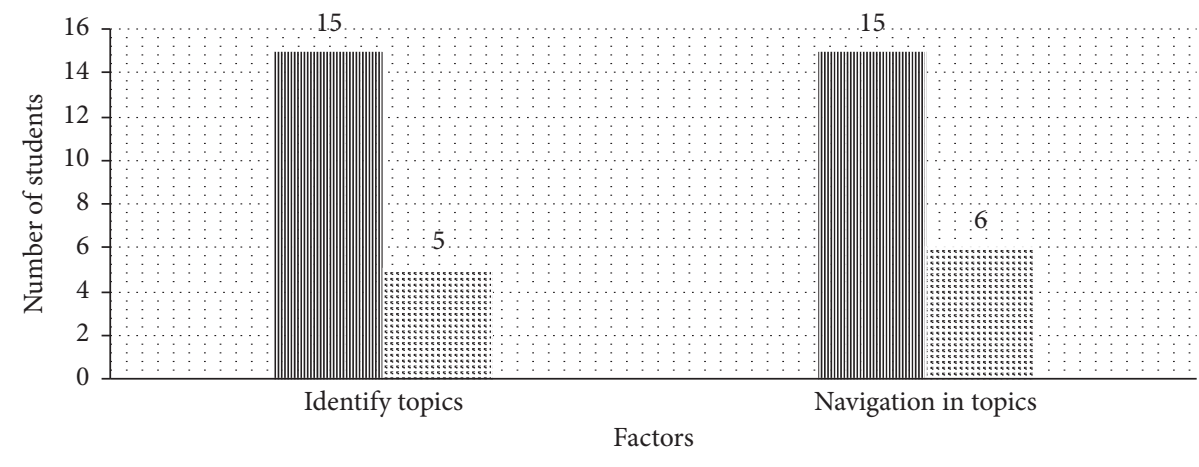

IIII Experimental group

i: Control group

Figure 8: Efficiency of the system.

TABLE 10: Efficiency analysis.

\begin{tabular}{|c|c|c|c|c|}
\hline S.no & Null hypothesis for the measure & Test conducted & Sig. & Result \\
\hline 1 & $\begin{array}{c}\text { Time required for identifying topics is the same for both } \\
\text { groups }\end{array}$ & $\begin{array}{c}\text { Independent-samples Mann-Whitney } \\
U \text { test }\end{array}$ & $.000^{1}$ & $\begin{array}{l}\text { Null hypothesis is } \\
\text { rejected }\end{array}$ \\
\hline 2 & $\begin{array}{c}\text { The distribution of navigation is the same across categories } \\
\text { of group type }\end{array}$ & $\begin{array}{l}\text { Independent-samples Mann-Whitney } \\
\text { U test }\end{array}$ & $.000^{1}$ & $\begin{array}{l}\text { Null hypothesis is } \\
\text { rejected }\end{array}$ \\
\hline
\end{tabular}

${ }^{1}$ The significance level is 0.05 .

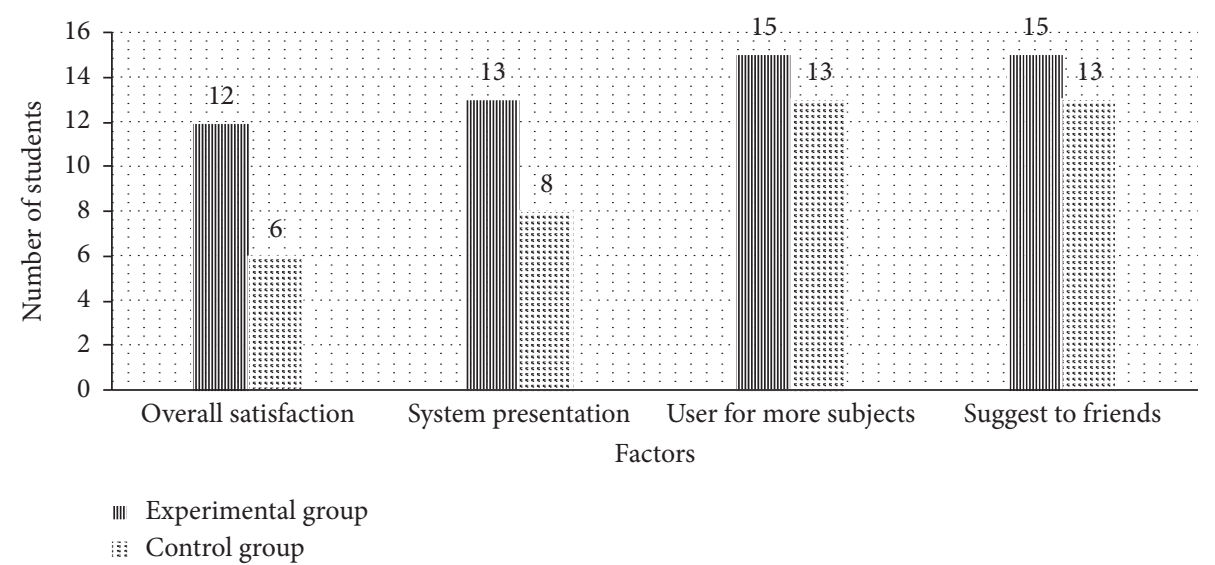

FIGURE 9: User satisfaction.

6.3. User Satisfaction. For user satisfaction, responses have been taken from both groups to know how much our experimental prototype fulfills the requirements of a user. Based on the statistics of responses, contents are better presented to the user, and the users suggest that the system will be better to incorporate other subjects too. We can see that measures taken for user satisfaction are enhanced for the experimental group as shown in Figure 9.

For ensuring that improvement is enhanced, we have applied independent-samples Mann-Whitney $U$ test for all measures associated with user satisfaction for $95 \%$ confidence interval. The null hypothesis is rejected as the value of $p$ is less than 0.05 , which is shown in Table 11 . It shows that the proposed prototype provides a better user experience.

6.4. Model Effectiveness. This is one of the most important aspects of the evaluation of the proposed model. Six measures were taken for assessment of the effectiveness. These measures include motivation, fairness of marking, usefulness, pinpoint weakness, memory load, and systems 
TABLE 11: Analysis of user satisfaction.

\begin{tabular}{|c|c|c|c|c|}
\hline S.no & Null hypothesis for the measure & Test conducted & Sig. & Result \\
\hline 1 & User satisfaction is the same for both groups & $\begin{array}{c}\text { Independent-samples Mann-Whitney } \\
U \text { test }\end{array}$ & $0.033^{1}$ & $\begin{array}{l}\text { Null hypothesis is } \\
\text { rejected }\end{array}$ \\
\hline 2 & $\begin{array}{c}\text { Level of the proposed system scalability is similar for both } \\
\text { groups. }\end{array}$ & $\begin{array}{l}\text { Independent-samples Mann-Whitney } \\
\text { U test }\end{array}$ & $0.033^{1}$ & $\begin{array}{l}\text { Null hypothesis is } \\
\text { rejected }\end{array}$ \\
\hline 3 & Content presentation is the same for both groups. & $\begin{array}{c}\text { Independent-samples Mann-Whitney } \\
\text { U test }\end{array}$ & $0.045^{1}$ & $\begin{array}{l}\text { Null hypothesis is } \\
\text { rejected }\end{array}$ \\
\hline
\end{tabular}

${ }^{1}$ The significance level is 0.05 .

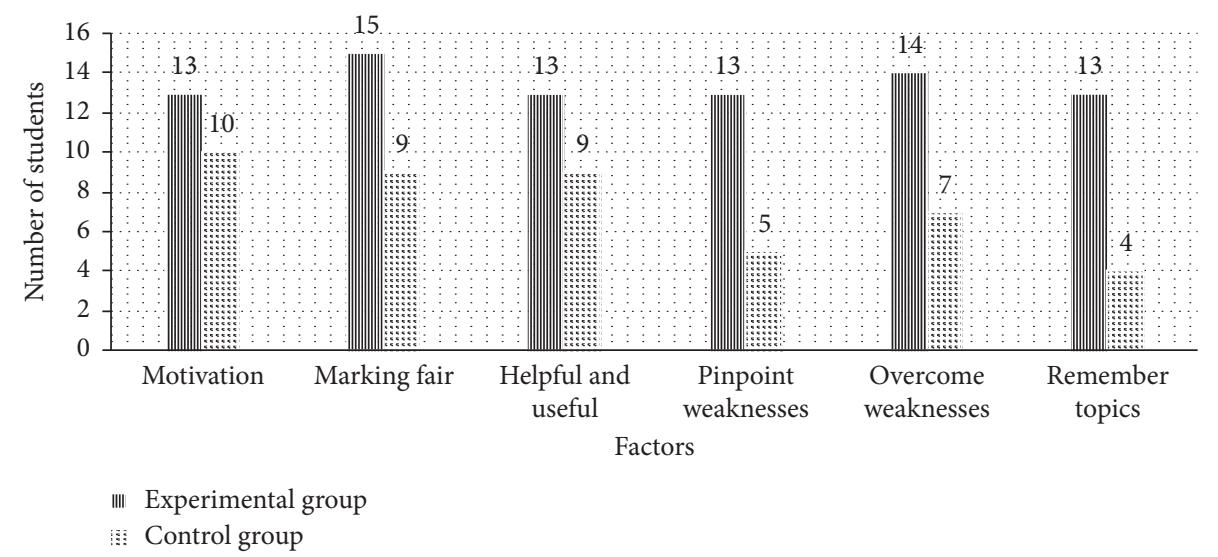

Figure 10: Effectiveness.

TABle 12: Analysis of model's effectiveness.

\begin{tabular}{|c|c|c|c|c|}
\hline $\begin{array}{l}\text { S. } \\
\text { no }\end{array}$ & Null hypothesis for the measure & Test conducted & Sig. & Result \\
\hline 1 & Motivation is the same for both groups & $\begin{array}{l}\text { Independent-samples } \\
\text { Mann-Whitney } U \text { test }\end{array}$ & $0.285^{1}$ & $\begin{array}{l}\text { Null hypothesis is not } \\
\text { rejected }\end{array}$ \\
\hline 2 & Marking fairness is the same for both groups & $\begin{array}{l}\text { Independent-samples } \\
\text { Mann-Whitney } U \text { test }\end{array}$ & $0.003^{1}$ & $\begin{array}{l}\text { Null hypothesis is } \\
\text { rejected }\end{array}$ \\
\hline 3 & Level of usefulness is the same for both groups & $\begin{array}{l}\text { Independent-samples } \\
\text { Mann-Whitney } U \text { test }\end{array}$ & $0.137^{1}$ & $\begin{array}{l}\text { Null hypothesis is not } \\
\text { rejected }\end{array}$ \\
\hline 4 & $\begin{array}{l}\text { Level of pinpointing weakness by the system is the same } \\
\text { for both groups }\end{array}$ & $\begin{array}{l}\text { Independent-samples } \\
\text { Mann-Whitney } U \text { test }\end{array}$ & $0.019^{1}$ & $\begin{array}{l}\text { Null hypothesis is } \\
\text { rejected }\end{array}$ \\
\hline 5 & $\begin{array}{l}\text { Overcoming the weakness from the system is the same for } \\
\text { both groups }\end{array}$ & $\begin{array}{l}\text { Independent-samples } \\
\text { Mann-Whitney } U \text { test }\end{array}$ & $0.037^{1}$ & $\begin{array}{l}\text { Null hypothesis is } \\
\text { rejected }\end{array}$ \\
\hline 6 & Reducing memory load is the same for both groups & $\begin{array}{l}\text { Independent-samples } \\
\text { Mann-Whitney } U \text { test }\end{array}$ & $0.000^{1}$ & $\begin{array}{l}\text { Null hypothesis is } \\
\text { rejected }\end{array}$ \\
\hline
\end{tabular}

${ }^{1}$ The significance level is 0.05 .

suggestions to overcome weakness. Figure 10 shows the comparisons for both the experimental and control groups.

However, to know that the improvement is meaningful, we have performed independent-samples Mann-Whitney $U$ test for its relative difference. The overall assessment is shown in Table 12, where we can see that the null hypothesis is rejected for measures such as fairness of assessment, pinpoint weakness, overcoming the weakness, and memory load, which shows that these factors are significantly enhanced during the experimental group's learning process. On the other hand, measures such as motivation and usefulness are enhanced, but statistically, their difference is not relatively significant which means that our prototype performs relatively better than the existing one.

\section{Conclusion}

Understanding student's learning preferences help us to know the way by which learner can learn easily and effectively. For the effectiveness of learning systems in the educational domain such as adaptive hypermedia, learning styles are used for content adaptation according to the user learning style. But learning styles have domain-wise variations and approaches based on learning styles mainly work in the context of single domain. We have provided a more effective means by incorporating its changeable aspects such as domain-wise learning style preferences in the user model.

To achieve the objective, we have proposed a robust and flexible model to update student learning style preferences 
according to their discipline. A web-based experimental prototype is developed for the assessment and validation of the proposed model. The proposed model is compared, and the experimental results show that personalization based on discipline-wise learning style variations becomes more effective. The results also show that adaptation based on domain-wise learning style variations enhances the learning outcome of these systems. The proposed research can be used in making the learning systems more intelligent for adapting contents. Furthermore, the proposed model also provides a foundation for upcoming learning-based solutions which required more refined adaptation rules as well as user models to incorporate features that are the true representations of their needs.

\section{Data Availability}

The data used to support the findings of this study are available from the corresponding author upon request.

\section{Conflicts of Interest}

The authors declare that there are no conflicts of interest regarding this paper.

\section{References}

[1] C. Froschl, "User modeling and user profiling in adaptive E-learning systems," Master Thesis, Springer, Graz, Austria, 2005.

[2] E. Knutov, P. De Bra, and M. Pechenizkiy, "AH 12 years later: a comprehensive survey of adaptive hypermedia methods and techniques," New Review of Hypermedia and Multimedia, vol. 15, no. 1, pp. 5-38, 2009.

[3] C. Mulwa, S. Lawless, M. Sharp, I. Arnedillo-Sanchez, and V. Wade, "Adaptive educational hypermedia systems in technology enhanced learning: a literature review," in Proceedings of the 2010 ACM Conference on Information Technology Education, pp. 73-84, ACM, New York, NY, USA, October 2010.

[4] E. Kurilovas, I. Zilinskiene, and V. Dagiene, "Recommending suitable learning scenarios according to learners' preferences: an improved swarm based approach," Computers in Human Behavior, vol. 30, pp. 550-557, 2014.

[5] V. Štuikys, "Context-aware adaptation of smart los," in Proceedings of the Smart Learning Objects For Smart Education In Computer Science, pp. 161-181, Springer, Berlin, Germany, November 2015.

[6] E. Kurilovas, I. Zilinskiene, and V. Dagiene, "Recommending suitable learning paths according to learners' preferences: experimental research results," Computers in Human Behavior, vol. 51, pp. 945-951, 2015.

[7] E. Kurilovas, S. Kubilinskiene, and V. Dagiene, "Web 3.0based personalisation of learning objects in virtual learning environments," Computers in Human Behavior, vol. 30, pp. 654-662, 2014.

[8] A. Jeghal, L. Oughdir, H. Tairi, and A. Radouane, "Approach for using learner satisfaction to evaluate the learning adaptation policy," International Journal of Distance Education Technologies, vol. 14, no. 4, pp. 1-12, 2016.
[9] A. Alam, S. Ullah, and N. Ali, "The effect of learning-based adaptivity on students' performance in $3 \mathrm{D}$-virtual learning environments," IEEE Access, vol. 6, pp. 3400-3407, 2018.

[10] C. Jones, C. Reichard, and K. Mokhtari, "Are students' learning styles discipline specific?" Community College Journal of Research and Practice, vol. 27, no. 5, pp. 363-375, 2003.

[11] H. M. El-Bakry, A. A. Saleh, T. T. Asfour, and N. Mastorakis, "A new adaptive e-learning model based on learner's styles, in," in Proceedings of the 13th WSEAS International Conference on Mathematical and Computational Methods in Science and Engineering (MACMESE'11), pp. 440-448, Catania, Sicily, Italy, November 2011.

[12] C. Martins, L. Faria, C. V. De Carvalho, and E. Carrapatoso, "User modeling in adaptive hypermedia educational systems," Educational Technology \& Society, vol. 11, no. 1, pp. 194-207, 2008.

[13] H. M. El-Bakry and A. A. Saleh, "Adaptive e-learning based on learner's styles," Bulletin of Electrical Engineering and Informatics, vol. 2, no. 4, pp. 240-251, 2013.

[14] M. A. Fernandes, C. R. Lopes, F. A. Dorca, and L. V. Lima, "A stochastic approach for automatic and dynamic modeling of students' learning styles in adaptive educational systems," Informatics in Education-An International Journal, vol. 112, pp. 191-212, 2012.

[15] A. Abyaa, M. K. Idrissi, and S. Bennani, "Learner modelling: systematic review of the literature from the last 5 years," Educational Technology Research and Development, vol. 67, pp. 1-39, 2019.

[16] A. C. Wintergerst, A. DeCapua, and M. Ann Verna, "Conceptualizing learning style modalities for esl/efl students," System, vol. 31, no. 1, pp. 85-106, 2003.

[17] D. W. Salter, N. J. Evans, and D. S. Forney, “A longitudinal study of learning style preferences on the myers-briggs type indicator and learning style inventory," Journal of College Student Development, vol. 47, no. 2, pp. 173-184, 2006.

[18] E. P. Rozanski and A. R. Haake, "The many facets of hci," in Proceedings of the 4th Conference on Information Technology Curriculum, pp. 180-185, ACM, New York, NY, USA, October 2003.

[19] E. Sadler-Smith and R. Riding, "Cognitive style and instructional preferences," Instructional Science, vol. 27, no. 5, pp. 355-371, 1999.

[20] A. Y. Kolb, The kolb learning style inventory-version 3.12005 technical specifications, Hay Resource Direct, Boston, MA, USA, 2005.

[21] H. A. Witkin, A Manual for the Embedded Figures Tests, Consulting Psychologists Press, Palo Alto, CA, USA, 1971.

[22] P. Brusilovsky, E. Schwarz, and G. Weber, ELM-art: An Intelligent Tutoring System on World Wide Web, in Intelligent Tutoring Systems, Springer, Berlin, Germany, 1996.

[23] R. M. Carro, E. Pulido, and P. Rodríguez, Tangow: Task-Based Adaptive Learner Guidance on the Www, Computer Science Report, Eindhoven University of Technology, Eindhoven, Netherlands, 1999.

[24] I. H. Beaumont, "User modelling in the interactive anatomy tutoring system anatom-tutor," User Modelling and UserAdapted Interaction, vol. 4, no. 1, pp. 21-45, 1994.

[25] M. R. Zakaria, A. Moore, H. Ashman, C. Stewart, and T. Brailsford, The Hybrid Model for Adaptive Educational Hypermedia, in Adaptive Hypermedia and Adaptive Webbased Systems, Springer, Berlin, Germany, 2002. 
[26] P. D. Bra and L. Calvi, "Aha! an open adaptive hypermedia architecture," New Review of Hypermedia and Multimedia, vol. 4, no. 1, pp. 115-139, 1998.

[27] J. Kay and B. Kummerfeld, "Adaptive hypertext for individualised instruction," in Proceedings of the Workshop On Adaptive Hypertext And Hypermedia At Fourth International Conference On User Modeling, Hyannis, MA, USA, August 1994.

[28] H. Hohl, H.-D. Boecker, and R. Gunzenhaeuser, Hypadapter: An Adaptive Hypertext System for Exploratory Learning and Programming, in Adaptive Hypertext And Hypermedia, Springer, Berlin, Germany, 1998.

[29] C. Boyle and A. O. Encarnacion, Metadoc: An Adaptive Hypertext Reading System, in Adaptive Hypertext And Hypermedia, Springer, Berlin, Germany, 1998.

[30] R. Zeiliger, Adaptive Testing: Contribution of the Shiva Model, In Item Banking: Interactive Testing and Self-Assessment, Springer, Berlin, Heidelberg, Germany, 1993.

[31] G. Weber, H.-C. Kuhl, and S. Weibelzahl, Developing Adaptive Internet Based Courses with the Authoring System Netcoach, In Hypermedia: Openness, Structural Awareness, and Adaptivity, Springer, Berlin, Heidelberg, Germany, 2002.

[32] P. Brusilovsky, E. Schwarz, and G. Weber, "A tool for developing adaptive electronic textbooks on www," WebNet, vol. 96, pp. 64-69, 1996.

[33] P. Brusilovsky and L. Pesin, "Isis-tutor: an adaptive hypertext learning environment," in Proceedings of the JCKBSE'94, Japanese-CIS Symposium on Knowledge-Based Software Engineering, vol. 94, pp. 10-13, Pereslavl-Zalesski, Russia, May 1994.

[34] P. Brusilovsky, L. Pesin, and M. Zyryanov, Towards an Adaptive Hypermedia Component for an Intelligent Learning Environment in Human-computer Interaction, pp. 348-358, Springer, Berlin, Germany, 1993.

[35] S. Ferrandino, A. Negro, V. Scarano, and Cheops, "Adaptive hypermedia on world wide web," In Interactive Distributed Multimedia Systems And Telecommunication Services, Springer, Berlin, Heidelberg, Germany, 1997.

[36] E. J. Brown, T. J. Brailsford, T. Fisher, and A. Moore, "Evaluating learning style personalization in adaptive systems: quantitative methods and approaches," IEEE Transactions on Learning Technologies, vol. 2, no. 1, pp. 10-22, 2009.

[37] P. Brusilovsky, "Methods and techniques of adaptive hypermedia," User Modeling and User-Adapted Interaction, vol. 6, no. 2-3, pp. 87-129, 1996.

[38] B. Peter, Adaptive Hypermedia: an Attempt to Analyze and Generalize, in Multimedia, Hypermedia, and Virtual Reality Models, Systems, and Applications, Springer, Berlin, Heidelberg, Germany, 1996.

[39] A. Kavcic, "The role of user models in adaptive hypermedia systems,"vol. 1, pp. 119-122, in Proceedings of the MELECON 2000 10th Mediterranean, vol. 1, pp. 119-122, IEEE, Lemesos, Cyprus, May 2000.

[40] V. Esichaikul, S. Lamnoi, and C. Bechter, "Student modelling in adaptive e-learning systems," Knowledge Management \& E-Learning: An International Journal (KM\&EL), vol. 3, no. 3, pp. 342-355, 2011.

[41] Y. Long and V. Aleven, "Enhancing learning outcomes through self-regulated learning support with an open learner model," User Modeling and User-Adapted Interaction, vol. 27, no. 1, pp. 55-88, 2017.

[42] E. Kurilovas, J. Kurilova, and T. Andruskevic, On Suitability Index to Create Optimal Personalised Learning Packages, In
International Conference On Information And Software Technologies, Springer, Berlin, Germany, 2016.

[43] R. Z. Cabada, M. L. B. Estrada, F. G. Hernández, R. O. Bustillos, and C. A. Reyes-García, "An affective and web 3.0-based learning environment for a programming language," Telematics and Informatics, vol. 35, no. 3, pp. 611-628, 2018.

[44] J. D. Guerra Hollstein, Open learner models for self-regulated learning: exploring the effects of social comparison and granularity, Ph.D. thesis, University of Pittsburgh, Pittsburgh, PA, USA, 2018.

[45] F. A. Dorça, L. V. Lima, M. A. Fernandes, and C. R. Lopes, “A new approach to discover students learning styles in adaptive educational systems," Revista Brasileira de Informática na Educação, vol. 21, no. 1, p. 76, 2013.

[46] F. A. Dorça, L. V. Lima, M. A. Fernandes, and C. R. Lopes, "Comparing strategies for modeling students learning styles through reinforcement learning in adaptive and intelligent educational systems: an experimental analysis," Expert Systems with Applications, vol. 40, no. 6, pp. 2092-2101, 2013.

[47] P. Anthony, N. E. Joseph, and C. Ligadu, "Learning how to program in c using adaptive hypermedia system," International Journal of Information and Education Technology, vol. 3, no. 2, pp. 151-155, 2013.

[48] S. Graf, S. R. Viola, and T. L. Kinshuk, "Representative characteristics of felder-silverman learning styles: an empirical model," in Proceedings of the IADIS International Conference on Cognition and Exploratory Learning in Digital Age (CELDA 2006), pp. 235-242, Barcelona, Spain, June 2006.

[49] C. A. Carver, R. A. Howard, and W. D. Lane, "Enhancing student learning through hypermedia courseware and incorporation of student learning styles," IEEE Transactions on Education, vol. 42, no. 1, pp. 33-38, 1999.

[50] S. Sosnovsky and P. Brusilovsky, "Evaluation of topic-based adaptation and student modeling in quizguide," User Modeling and User-Adapted Interaction, vol. 25, no. 4, pp. 371-424, 2015. 